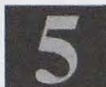

\title{
¿Qué medidas considera indispensables en una estrategia económica para el próximo quinquenio?
}

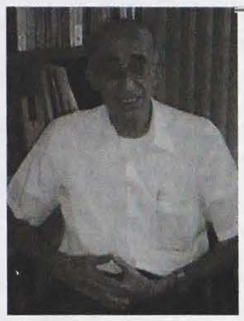

Humildemente vuelvo a citar mi artículo: "Economía sin plan, sin mercado y sin autocrítica" (ECA, junio 2003), por que al menos es bueno para criticarlo. Creo que hay que volver a los Planes de Desarrollo, esrilo década de 1970, comenzando por decir la "verdad". El BCR acaba de editar la matriz 2000, que tal vez algo podría orientar. (La acabo de recibir, pero no he tenido tiempo de curiosearla). Viendo los análisis de FUSADES apreciamos que se hace necesaria una revisión total de las visiones y políticas económicas...

Javier Ibisate,

UCA

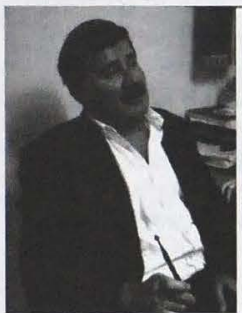

Roberto Rublo, FUNOE

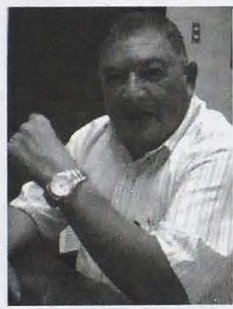

Jorge Barraza lbarra,

UTEC

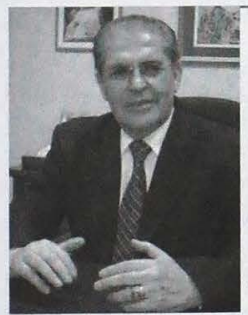

Más inversión y más capacidad exportadora es necesaria para incrementar el pastel productivo y generar más empleo; paralelamente habrá que implementar mecanismos eficaces que permitan una distribución más equitativa del ingreso por habitante y potenciar los niveles de ahorro como fuente primordial de la inversión. Habrá que reducir la brecha comercial externa, la deuda pública, el déficit fiscal y afrontar la deuda previsional, para propiciar una mejor calidad de vida y un crecimiento financieramente sano. El crecimiento con equidad es tan necesario en una pretensión de desarrollo, como lo es elevar los niveles educativos, mejorar los sistemas de salud y las condiciones habitacionales de la mayoría de la población. En este último sentido gran parte de la inversión social tendría que tener una cobertura que cubra estas áreas.
La situación en que nos encontramos no es fácil, una salida es hacer un esfuerzo por aumentar más los impuestos directos, evitar la evasión y la elusión que en muchos casos se da desde el sector financiero, y que por el momento es legal. Es necesario revisar todos los mecanismos legales que puedan existir. Creo que aquí hay sectores que tienen excelentes condiciones, son los que más crecen, por lo que deberían pagar más, tienen que dar su cuota de sacrificio, por su propio bien, a largo plazo, para que tengan más clientes.

Como recomendación creo que es esencial pedir una cuota de sacrificio a los sectores más dinámicos y de mayor ganancia, para que esos fondos se orienten adecuadamente a la inversión pública, pero dirigirla más a los sectores productivos: a la agricultura, industria local, y que lleve esa inversión a cierto sectores que pueden pegar jalonamiento. Aquí hablo del proyecto de La Comisión Nacional de Desarrollo.

Pueden ser muchas, en función de lo que el gobierno del señor Saca tenga en mente como su política de desartollo. Pero a mi juicio, hay una que considero vital: por sobre todo, generar empleo suficiente y garantizar el poder adquisitivo de las familias más desprotegidas. En el campo de las políticas sectoriales parece urgente dos áreas que deben ser focalizadas en el corto plazo, una es la reactivación del sector agropecuario, y la otra, el fomento y fortalecimiento de las micro, pequeñas y medianas empresas. 


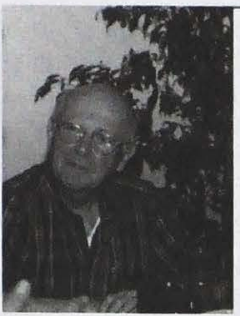

Héctor Dada Hirezl, Olputado COU
Lo primero es aceptar que el esquema de política económica que se ha seguido no ha rendido los frutos proclamados y que se necesita cambiarlo. Debe definirse una política de desarrollo de mediano plazo, en la que se de al aparato del Estado la función orientadora y supervisora que le corresponde. Las aperturas comerciales con el exterior, por bien orientadas que sean, no son en si mismas políticas de desarrollo, y más bien deben ser concebidas como una pieza entre otras de un esquema coherente de desarrollo. Hay que orientarse a recuperar la capacidad producriva del país sobretodo en el área rural, apoyando decididamente a los pequeños y microempresarios.

Hay que distribuir geográficamente la inversión pública, sobretodo hacia aquellas áreas menos favorecidas (lo que conlleva un serio ordenamiento territorial y una verdadera estrategia de desconcentración y descentralización de la actividad estatal), apoyando el desarrollo y en no pocos casos la generación de actividades locales productivas y de servicio.

Es indispensable rediseñar la institucionalidad de la banca estatal para que sea una verdadera banca de desarrollo. La integración centroamericana debe ser concebida como una estra tegia de desarrollo de la región como un todo, lo que requiere de organismos regionales supranacionales que orienten con mano firme el proceso. Considerar la política social como parte integrantede una política de desarrollo, sin la cual las metas económicas serían muy difficiles de alcanzar.

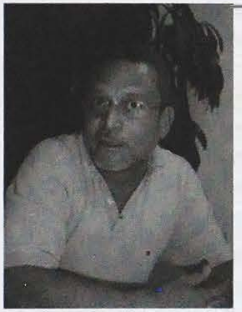

Carlos Brlones, FLACSO
Se necesita que tanto el gobierno, los sectores empresariales privados y las instituciones académicas implementen una estrategia activa de búsqueda de innovaciones productivas que permita desarrollar condiciones de cambio estructural en el tejido económico, para identificar cuales puede tener un impacto más rápido y cuales tienen más debilidades, además de identificar cuales son las que tiene mayor futuro.

Es necesario tener un diagnóstico de las actividades más rentables y potenciales para poder encontrar las soluciones, porque es falso de que sólo a través del mercado pueden identificarse estas actividades, tal y como lo aseguraba el Consenso de Washington. Es necesario de que los pafses desarrollen estrategias activas y sostenerlas socialmente.

Se trata de encontrar una estrategia, legitimarla y sostenerla. No se trata de crear economías de enclave, que eso es a lo que algunos sectores sociales se han opuesto pues creen que si la economia se orienta hacia el exterior, significa que se fundará en políticas de bajo salarios y demasiado dependiente del exterior. Eso no es cierto, por ejemplo Alemania es de los palses más exportadores y está fundada en un modelo de economía social de mercado orientada a los mercados mundiales, pero hacia adentro construyó un sólido tejido social.

Definitivamente no podemos superar las tasas históricas de crecimiento si no nos orientamos hacia los mercados internacionales. Debemos descubrir que nuevas actividades y sectores podemos desarrollar $y$ combinarlos con políticas de actividad comerciales internas. El turismo podría por ejemplo ser una de esas actividades. 